\title{
A Comparative Study on the Stages of Myths Where Nature Appears Sympathetic in Greek \& Persian Myths
}

\author{
Hiam Gerdabi \\ Sharif University of Technology, Iran \\ Nasrin Faghih \\ Alzahra University, Iran
}

Received: 10-02-2015

doi:10.7575/aiac.ijclts.v.3n.2p.66
Accepted: 29-03- 2015

Published: 01-04- 2015

URL: http://dx.doi.org/10.7575/aiac.ijclts.v.3n.2p.66

\begin{abstract}
During a mythical quest, a typical hero undergoes certain ordeals to achieve the heroic goal which sets him/her on the path of adventure in the first place. Facing the difficulties, the narrator offers help not only through the internal powers of the hero's soul but also through a variety of external forces (natural/supernatural). In Greek and Persian mythology, heroes sometimes receive help from nature as a source of independent power which can bring about changes. The current study aims to hold out a few cases of natural changes in legendary quests that take ordinary natural phenomena out of their path affecting the quest results. Joseph Campbell's list of stages of a myth is to be used for juxtaposing the natural phenomena in the myths in order to decide about the part of the legend where nature leaves a mark. The result of the study is expected to categorize different types of heroes that appear in Greek and Persian myths. Furthermore, the relationship between heroes and nature will be examined; as the Persian hero receives the natural interference during the ongoing stages of their quest as help, while the Greek hero receives the effect of nature after their death. All these are supposed to reveal the reward mechanism and how it reflects on the type of measures taken by nature.
\end{abstract}

Keywords: Archetypes, Mythical Hero, Structure of Myths, Reward, Persian Hero, Greek Hero

\section{Introduction}

Mythology and mythical characters have been among the most debatable genres studied by the literary scholars. Their historical, cultural, artistic and structural values are among the few reasons behind their importance. The aspects of myth to be studied have been elaborated on by many scholars such as Des Bouvrie who observes "We have to ask about the cultural effect that myth receives also we must consider how the human mind does in fact function in a special 'mythical' way, studying its relationship to conscious reasoning" (2002: 11). A more comprehensive definition of myth has been put forth by Claude Calame:

Myth is not an entity with any ontological existence, but rather a Western category which originated in the early days of anthropological thought, during the Enlightenment. As a spatially and temporally marked tool of classification, the category "myth" is generated by the act of looking at the cultures of others from a Eurocentric perspective. (1999: 121)

Man's cultural and internal tendencies in ancient times pushed him to create characters who have tried to push the limits, go through adventures and change the world from different perspectives. These individuals may have been involved in cases that led to either an upheaval in their own personal life in a drastic manner or a change in the lives of their fellowmen. Even though communication among nations at the time of narrating myths is considered scars compared to more recent era, many common points have been later discovered that oddly seem analogous to eachother. For the first time in 1919, Carl Jung in his essay Instinct and the Unconscious introduced the term archetypes to refer to recurrent trends and approaches in myths. Following his coinage, Maud Bodkin came to offer a more precise account of the topic. She offered a framework of Archetypal Criticism and categorizing the common stages of a myth into a plausible list. In her book Archetypal Pattern in Poetry she targeted the issue that there are some literary motifs that have an eternal durability and these motifs justify the use of the term archetypal. She considered these concepts to be of special interest to the students of psychology and literature (1934:5).this primary approach mostly was focused on categorizing the stages of a hero's quest.

\subsection{The Structure of Myths and Functions of a Hero}

As it was previously mentioned, a rough categorization of main steps in a myth was offered in the early 1930s. Those works were complimented by a more meticulous list of twenty one stages by Propp in his seminal work Morphology of the Folktales (1928). What Propp has added to previous list is how he has gone through a bigger volume of myths that 
had a more precise list compared to his other counterparts. It is worthy to mention that Propp has used at least two distinct types of structural analysis in folklore. He has confirmed this in the preface of his book by debating that the structure or formal organization of a folkloric text is described following the chronological order of the linear sequence of elements in the text as reported by an informant. Thus if a tale consists of elements A to Z, the structure of the tale is delineated in terms of the same sequence.

Joseph Campbell in The Hero with a Thousand Faces (1949) elaborated on many common patterns running through hero myths and stories from around the world. Campbell counted the axiomatic structures that almost every mythical hero goes through at least a few of those structural stages which he calls "monomyths". According to his definition, a hero's existence in a world is considered ordinary or uneventful by those who live there. Often the heroes are considered odd by those in the ordinary world and possess some ability or characteristic that makes them feel out-ofplace. As Campbell goes further the practical phases of the hero's path are counted for. He introduces some common stages including:

1. The call of adventure

2. Refusal of the quest

3. Accepting the call

4. Entering the unknown

5. Supernatural aid

6. Allies/helpers

7. Tests and supreme ordeals

8. Reward and the journey home

9. Master of two worlds/resigning the world

Little attention was paid to analyzing the hero himself. Later Strucrturalists came to heed about this aspect as well when Todorov in his book Facing the Extreme (1997) distinguished between two types of heroes, one of which may be morally commendable, the other being more a matter of living up to images of honor. "While the heroism of honor encourages the agent to think of himself in aesthetic terms, that is, in terms of appearance and style, the heroism of responsibility encourages the agent to think of himself in moral terms, that is, in terms of his obligations to other persons"(1997:11). It is not only death that defines the hero but Todorov puts up some traits to depict a good hero who is decisive and effective but, at the same time, affectionate and temperate; he is not driven by ideology. Since the present study is going to focus on examples from either type of the mentioned heroes it might alsobe plausible to consider these characters protagonists. A more detailed listof character types was put forth by Voytilla (2003:7) in which he categorized the characters in a typical myth as following:

1. Hero "to serve and sacrifice"

2. Mentor "to guide"

3. Threshold Guardian "to test"

4. Herald "to warn and challenge"

5. Shape-shifter "to question and deceive"

6. Shadow "to destroy"

7. Trickster "to disrupt"

In defining the function and motif of each of these types, he tends to incline towards Voytilla's basic distinction between two main types of heroes:

The Hero's Journey may be a challenge of personal growth: to win a competition, to heal a wound, or to find love. Heroes may also need to answer Calls to Adventure where physical lives and even the fate of the world are at stake. These Heroes must learn to accept the sacrifice of life and limb for the service of others. (1999:24)

It is noteworthy that the heroes chosen for this research do not necessarily go through all these stages. As Campbell himself brings examples in his books, several nations have succumbed to the mentioned monomyth structure in order to point out certain aspects of their heroes or protagonists. Archetypal criticism tends to elicit the common stages of myths in addition to common traits attributed to the characters who are considered either hero or antihero.

According to John Hinnels, myths are the mirrors reflecting visions beyond time; where history and archeology are silent, myths speak and bring people's culture to our time and give us access to the depth and extent of thoughts of some unknown but wise people (quoted in Amozegar, 1998: 7). Joseph Campbell has maintained, myths are clues to our deepest moral potentials and can lead us to happiness, ecstasy and even inspiration (2002:13).

The role of nature as an independent source seems like a common ground as well which can fall under a few of Campbell's categories. Sometimes nature plays an assisting role in a hero's life and quest while in other cases it may act like a comforting force that helps to reduce the pain of hero or the people who have lost him.

The instances required to confirm or reject the effect of nature on myths had better be taken from a pool of myths from different countries since it is supposed to clarify the stages and functions of myths in various cultures. This urges the 
reader to find out more about the comparative literature. De Zepetnek has generalized the type of insight one can get from comparative literature "First, the knowledge of more than one national language and literature, and/or the knowledge and application of other disciplines in and for the study of literature and second (1999: 13). Some studies followed aiming to offer different aspects of comparative literature one of them was conducted by Hutcheon and Mario in their Rethinking Literary History, where literary history is re-thought 'away from the concepts of nations and nationalisms' through the concept of nodal points, where different cultures come into contact, and from which different historical, artistic, cultural forces irradiate (1994: 104).

The aim of this paper is to draw conclusions based on the features that appear in the myths and to categorizethe functions apparent in them. Therefore, the choice of sources to look into was made based on a few reasons. Most importantly, Metamorphoses by Ovid (Greek) and Avesta (Persian) are considered among the most ancient works survived from these nations containing references to myths of their times. Interestingly, the Greek book is not necessarily a religious manuscript while Avesta is the religious collection that is attributed to the theological believes and rituals of Ancient Persia. This brings the reader to contemplate about the impact of religion and monotheism on Iranians from a very early time. The Greeks, on the other side, have more collections of myths and heroes in accordance with their polytheism starting with Ovid. To be more precise, these two works cannot be claimed the only two of their kind but they are the most referred to after all these years and the collection of myths available in them is considered the most comprehensive to serve the purpose of the current research.

\subsection{The psychology of reward}

The concept of reward has been a debate topic in psychological arena. This topic goes as far back as Skinner's Stimulus-Response theory where he asserted "It simply specifies a procedure for altering the probability of a chosen response (reaction)... Learning is said to take place because the reinforcement is pleasant, satisfying, tension reducing, and so on (1950:78). This reward or as Skinner calls it reinforcement was investigated further, years later, it appeared that offering a direct and predictable rewards would lead to the opposite results. According to Tegano et al the first thing that is damaged by extrinsic reward is creativity of performance (1991: 119). Any case of reward that is too obvious and highlighted can demotivate people and eventually stop the process of creativity. Apart from that, determination starts to fade as soon as one has become too reward oriented. What one observes from outside is the individual who is trying to reach a goal, yet Deci and Ryan noted that while performing a task, the decrease in intrinsic task interest resulting from expected reward will be reversed by high performance motivated by the prospect of reward (1985: 36). Therefore, the only way to be able to judge whether the individual is acting based on intrinsic motivation is to withdraw the reward and see if the performance level stays the same. Having elaborated on these theories regarding reward, there will be a discussion on how nature as an extrinsic reward affects the internal motivation of mythical heroes from the mentioned myths.

\section{Methodology}

The current study will initiate by short narration of the six myths chosen followed by thethree variables that form the method of this research. The concept of heroism and mythical hero in particular is the basis over which all the upcoming analyses are placed. According to Nietzsche

heroism is related to the aesthetic domain,the instincts that delight in war and conquest ... the beauty, wisdom, power, splendor and dangerousness of the type 'man', concluding that "the higher man is distinguished from the lower by his fearlessness and his readiness to challenge misfortune" (1990:103).

The categorization will initiate by drawing on the differences among the types of heroes taken from Todorov's categories (1997), this two types of heroes (individualistic and national) are attributed to Greek and Persian myths respectively. The other source of discrepancy among the two nations' myths is the functions of the myth during which the hero is influenced by nature; it is worthy to note that Campbell's categorization (1949) is exploited at this point. Those stages of myth where nature comes to interfere are considered significant as soon as they are linked to the award mechanism that is proposed by Deci\& Ryan (1985) who concluded the amount of determination and creativity of the participant with regard to the type of award offered.

\subsection{Greek Myths with a Touch of Nature}

For referring to the myths collected by Ovid, Henry T. Riley's translation of Metamorphoses was used. Riley refers to the book briefly as follows:

The Metamorphoses of Ovid are a compendium of the Mythological narratives of ancient Greece and Rome, so ingeniously framed, as to embrace a large amount of information upon almost every subject connected with the learning, traditions, manners, and customs of antiquity, and have afforded a fertile field of investigation to the learned of the civilized world. To present to the public a faithful translation of a work, universally esteemed, not only for its varied information (1893:iii).

As it was earlier elaborated, heroes in ancient myths could have been categorized under different types based on their goal and fate. The protagonist chosen from Greek myths are taken from Metamorphosis by Ovid. Three stories selected 
due to their reference to role of nature and its connection to hero's fate. It is noteworthy that the myths here do not necessarily narrate the story of heroes who fight for some external villain or evil force; they rather wish to break human boundaries and be the first person who goes off the bitten path.

The first hero to discuss is Narcissus whose myth is mentioned in book III: 437-473. Echo is a fair nymph who has been cursed; therefore she cannot say anything except for repeating what she hears. This condition has forced her to live in the woods where hardly anyone passes by. Once, a very fair young man named Narcissus is wandering in the woods and accidentally passes by the place where Echo is hiding. She sees him and at the first glance falls madly in love with him. Because of the curse, she cannot use her own words; yet incidentally the following conversation takes place:

By chance divided from his trusted friends, cries loudly, "Who is here?" and Echo, "Here!" replies. Amazed, he casts his eyes around, and calls with louder voice, "Come here!" "Come here!" She calls the youth who calls.-He turns to see who calls him and, beholding naught exclaims, "Avoid me not!" "Avoid me not!"returns. He tries again, again, and is deceived by this alternate voice, and calls aloud; "Oh let us come together!" Echo cries, "Oh let us come together!" (Metamorphosis: 443)

As soon as he finds out about her curse, he pushes her away in a very cruel manner and leaves. In Campbell's word he refuses to take the call. Echo's cry from her broken heart reaches the heavens and the Gods condemn him to fall in love with the first thing he sees. He is passing by a silver fountain where he falls in love with his own reflection in the water and stays by that water until he dies shortly after. When he dies, the flower Narcissus grows in his corps' place. This is considered the first appearance of this flower in nature.

The story of Pyramus and Thisbe also falls under the category of interference of nature. They are a couple whose parents are rivals and they are not allowed to be wed. Yet, they have found a crack in the wall which separates their houses and communicate through it. They decide to see each other outside the town under a Mulberry tree and run away to be able to get married. Thisbe arrives first, but upon seeing a lioness with a mouth bloody from a recent kill, she flees, leaving behind her veils. When Pyramus arrives he is horrified at the sight of Thisbe's veil, assuming that a fierce beast had killed her. Pyramus kills himself, falling on his sword, and in turn splashing blood on the white mulberry leaves. Pyramus' blood stains the white mulberry fruits, turning them dark. Thisbe returns, eager to tell Pyramus what had happened to her, but she finds Pyramus dead under the shade of the mulberry tree. Thisbe stabs herself with the same sword. In the end, the gods listen to Thisbe's lament, and forever change the color of the mulberry fruits into the stained color to honor the forbidden love.

Finally, the story of Phaethon (Book II:31-48) also seems to fall under the category of natural effect on a hero's fate. He is the son of Sun and when he finds out about his real father, he sets out to meet him. The Sun is accepts his son with an open arm and Phaethon asks to take the father's carriage through the sky for one day instead of him. In spite of all warnings and uncertainty on the side of the father, Phaethon does he take the carriage and sets to his journey through the sky. Very soon he knows that he cannot control the horses which could be considered the phase of a hero's journey that Campbell distinguishes as crossing the threshold.The sun approaches the earth causing the mountains to melt, the rivers to evaporate and finally the earth complains to the gods. Jupiter sends a thunderbolt which kills Phaethon and he fall on the ground. His sisters mourn so much for him around his tomb stones that they turn into Poplar trees. Their tears still flow, and hardened by the sun, fall as amber from the virgin branches, to be taken by the bright river and sent onwards to adorn Roman brides.

Vogler elaborated on Campbell's idea of resurrection by pointing that the hero is reborn or transformed with the attributes of his ordinary self in addition to the lessons and insights from the characters that he has met along the road. In order to draw a connection between the mentioned myths, it is possible to categorize nature's role in resurrecting theme(2007:9). Narcissus is flower (natural phenomenon) that was created for the first time after the fair young man died. This can be considered as a post mortem effect; therefore Narcissus has passed by the final stage of a heroic act from Campbell's list. Mulberry tree did exist before Pyramus and Thisbe; however nature showed its sympathy by turning the color of the fruit dark to honor the blood color of lovers who fight for their forbidden love. Once again the heroic quest came to be affected by nature on his final scene( master of two worlds). Phaethon was killed because of following his ambition to rule the light in the sky for one day. His sisters turned into poplar trees which did exist by then still they were turned into an already existing natural phenomenon to mark their brother's grave. As it is obvious nature does show modifications in the course of these stories either by creating a new element or by changing and already existing element or by reproducing an already existing element in order to mark a certain myth's fate having accomplished the heroic act's other stages by the debated heroes.

\subsubsection{The Persian Myths and the Role of Nature}

The Persian myths are taken from Stories from Ancient Iran by Dr. Ehsan Yarshater (1972). The book is a collection from all the major ancient stories from Avesta and other mythical collections from similar time spans. The narrations used here are taken from Avesta, nevertheless direct narration from Avesta is somehow difficult because it mostly implicitly mentions the myths while Yarshater has recounted the myth more practically. According to the electronic version of theDictionary of Britannica: 
Avesta is the sacred book of Zoroastrianism containing its cosmogony, law, and liturgy, the teachings of the prophet Zoroaster (Zarathushtra). The Avesta is in five parts. Its religious core is a collection of songs or hymns, the Gāthās, thought to be in the main the very words of Zoroaster. They form a middle section of the chief liturgical part of the canon, the Yasna, which contains the rite of the preparation and sacrifice of haoma. The Visprat is a lesser liturgical scripture, containing homages to a number of Zoroastrian spiritual leaders. The Vendidad, or Vidēvdāt, is the main source for Zoroastrian law, both ritual and civil. It also gives an account of creation and the first man, Yima.

Afrasiab (1972: 58) is a king from the land of Turan who has been inaugurated as a villain in many mythical stories as

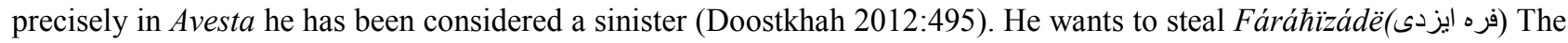
Divine Glory which is embodied in form of a falcon and is flying loose in the jungle. The falcon slips away each time Afrasiab tries to snatch it. For capturing the divine creature, the Turanian king has to take off his clothes and swim into a famous mythological lake namedFarakhkart/Farãkhkárt/ as the bird flies over the other side of the lake when it feels Afrasiab is approaching. He tries three times and each time he fails to capture the falcon, there appears a newriver banking from the main lake to trace the path through which the falcon has escaped in order to stall the villain from following the divine glory. Finally, he gives up and the divine glory flies to reach the righteous king that deserves to have it.

ArashKamangir/Kámãngër/ (1972:11) is a hero is remembered for his tremendous sacrifice. Amozegar (2009:69) has pointed that Arash has been implicitly mentioned in Avesta. There has been a long battle between Iran and Turan two neighbor countries. After many losses and casualties the enemies decide to put an end to this feud by designing some sort of task. One of the angels named Espandar Math /ĖspándãrMáð/ rules among based on which the representatives of both armies should assign an archer from among the Iranians. He shall shoot an arrow and as far as the arrow goes that will be the boarder among the two countries. Arash is known as the best archer among his fellows; therefore he is selected to draw the line of destiny between his homeland and the land of the enemies. He and all of his friends know that he will not survive after releasing the arrow as he is supposed to consume all the energy he has. As he stands there preparing for the shot, the earth grants him some energy. As soon as he releases the arrow, the wind blows in a direction to hold the arrow in the air for longer time and also to direct it as far east as possible. Quoting from the $33^{\text {rd }}$ Yasht in Avesta(collected by Doostkhah 2012) the nature's reaction has been described as "The pure mist from which clouds are formed started moving, the southern wind blew and drove the mist onward. As a result rain and hail start drenching the land and all were praying" (2012:330).Finally after half a day the arrow falls beside the JeyhoonRiverJeyhun /dzéihûn/ which made Iran's boarder vaster than before. Although Arash died because of this event but his sacrifice was immortalized.

Zoroaster the prophet was born under unusual circumstances (1972:65). The divine spirit is sent down to earth by two angels Bahman /báhmán/andOrdibehesht /ördibéhéft/. They carried it on a branch of a holy tree. Then they planted the Holy Spirit on a tree that was housing two birds. The whole ground around the tree was purified. Even though a snake tried to swallow the birds on the purified tree, the Holy Spirit destroyed the snake and the birds were kept alive to guard the Holy Spirit. This could be referred to as the supernatural aid.Poorvashasp /pûrváfásp/(Zoroaster's father) was inspired in a dream to take 6 cows and have them gaze beside the holy tree, and then he and his wife Dagdu /dãgdů/were to drink from the milk they would take from those cows after gazing. Following the divine inspirations, Dagdu became pregnant and her son became the prophet of Zoroastrians. Amozegar and Tafazoli have discussed the importance of Zoroaster's role: Zoroaster in that pure light just like Amshaspandan /ámfãspándãn/ was created in another world so that he submit to the religion completely and comprehensively and spreads it around the world (2002:28).

As it was recounted, the nature took different roles in the mentioned myths. It helped the divine glory to escape Afrasiab in the stage where he entered the unknown as an antagonist who could have used it for inglorious purposes had he reached the bird. In this case an already existing natural element was created in that spot to stop the villain. Arash was aided by the earth and the wind as soon as he accepted the call of his fellow countrymen to magnify the boarders of his country and basically represent the rivalry of his fellow men. Wind was the natural constituent that was supernaturally sent to direct the will of gods in the story. Finally, a few elements of nature carried the divine spirit that was sent down to earth so that Zoroaster could be conceived by the right woman and find his place in earth parallel with the supernatural helps assigned for this case by gods. The prophet was soundly delivered to the right parents because of natural elements' contribution such as the tree, the cows, and the ground.

\subsection{Analyzing the Role of Nature}

\subsubsection{Natural Rescue in Specific Functions of Myths}

Having picked the six myths from among the ocean of available myths in Persia and Greece, the next step would be to justify this choice by considering these myths a match for the current hypothesis. These stories have certain prevalence over their other counterparts, in that nature comes to act like an independent external force where divinity or men do not have much of effect. Nature acts purely out of free will to abet the hero and leave a finger print of the overall story structure. The reader is further mesmerized when he/she contemplatesabout and figures out how the role of nature is neither paramount nor negligible. To be more precise, nature being independent from human and divine forces, asserts 
its independence by playing a certain type of role that neither it can be firmly considered marginal, nor can it stand out as a key role.

There are definitely some other stories that hold up nature and its elements as responsible for fulfilling the purpose that mythical characters have. The ones chosen here are picked since they differentiate between the stages of a heroic act taken from Campbell's list in order to offer the natural help. It is necessary to point what Campbell calls the helper on his $6^{\text {th }}$ level is not the same as nature that is being discussed here. Nature's help does not substantially act as a fundamental factor in the story line; on the contrary, what makes nature's role special in these myths is how the reader is surprised by seeing this type of interference.

Before the detailed analysis starts, it is worthy to distinguish the type of person that is regarded as a hero in either the Persian or Greek myths. These two nations have separate merits associated with a hero. An internal factor appears when one is studying the differences and that is the type of purpose that each hero follows. The Greek side of the equation seems more preoccupied with breaking boundaries and having individual adventures, this is the persona considered morally commendable by Todorov. No one asks or requires them to go on the path that they take. They do it because they want to break the rules and go off the beaten path. Death appears like an interesting step amongst these three cases as Todorov justifies it "The hero is not only insensitive to the value of individual lives, but he defines himself in relation to death, since death, or, more exactly, the willingness to confront death, manifests his dedication to some ideal" (1996:47-48). On the other side, the Iranian heroes or even villains are striving for the national or group values. Todorov regards this group as the ones who hold on to the code of honor by heeding about the interest of the others. They wish to cease power, bring glory to the nation, or spread the word of their worshipped one. They seem like sacrificing for the benefit of anyone but themselves. The obvious division between individualistic hero (Greek) and national hero (Persian) sets this study on the right path to clarify not only the way in which nature interferes but also the reason why nature does so. Baharhas intensified this point by disputing:

In Persian myths we do not have tragic concepts like the Greek patterns... a villain faces an angelic persona then the villain kills the good character in the worst possible manner. This is how we narrate sad stories. Yet in Greece, there is no necessity for villainous character; some characters and factors face each other and determination pushes them toward their doom (1998:241).

The functions of myths applied to the Greek stories seemed to cover a bigger range from among the list offered by Campbell. The discussed Greek heroes received a call from various sources (Internal/ External), their acceptance was not assured. No supernatural aid or reward was narrated; yet they all went through a test or ordeal. The ordeal was a surprise that pushed the hero to take drastic majors. Finally, nature seemed influential after the death or defeat of the hero/heroin as they reached the ultimate function. A mark was left on the nature to remember the sacrifice made by the hero. During the adventure picked, no natural element seemed to interfere with the process which ended up in the discussed heroes' death; therefore the sympathy of nature appeared only to hold a memoriam which symbolically made the people to remember a dauntless soul's adventure.

On the other side, in Persian myths there is a call for adventure that serves the public interest, following the acceptance of the call they enter the unknown land, supernatural aids and other types of help are offered. Death is not necessarily the final stage of their quest. Nature has its elements involved to set the hero free or at least help him to achieve the noble purpose that he has set out for. There is a return home for two of the mythical characters mentioned during whose adventure; nature plays a major role to affect the process of the quest.

Now that the overall scheme of the functions along with what nature has to offer in different cases and purposes of Persian and Greek mythical heroes are discussed, it is time to draw on the reasons behind these discrepancies. According to Thompson comparative studies give us a good opportunity for assessing how comparative history can contribute to modem knowledge ... in The Comparative Imagination (1998:48). Based on this assumption one can conclude that individuality seems like a value for Greeks while in Persia, a hero is someone who sacrifices his life and comfort to bring comfort to his fellow men. Nature can be assumed a rewarding type of help that appears when a public hero needs help, while an adventurous soul is mostly remembered by nature after his/her death. The Greek hero creates his/her own adventure by defining an action that has provoked his/her curiosity or even sense of safety. When one reads one of three Greek stories brought here, it seems as though the creator of the myth has left the protagonist loose and expects the individual to be fearless and risk taking; therefore the type of pattern drawn from this sort of heroism is to encourage the audience to find their own way and move toward individuality and independence. The Persian epic creators wish to form the exact opposite view by encouraging the audience to adhere to national values, become a team member and expect rewards when they do something to boost the group's/nation's situation. These rewards cover a wide range of natural (possible) and supernatural (impossible) to lure the person to give up his comfort and commit sacrifice.

If one considers nature and its interference as some sort of reward, the Persian heroes who are given extrinsic incentives can be considered internally less creative and less determined. As it was discussed in the introduction section, the external reward has negative side effects; therefore one can deduce that Persian heroes did not perform their tasks independently. It might be the fact that human being (whether a hero or not) finds it difficult to succumb to group values and prefers to seek his/her own benefits. Incentive is achieved the best when the task has been planned and 
devised by the person him/herself. When one has to risk his safety and tranquility for group values, some sort of external reward is required. On the other hand, the Greek heroes who do not follow a call of a group who require their sacrifice; they set out on the journey quite independently and do not expect the incentive of nature to help along. Nature, this time, does offer a reward which is not to reinforce group values but to boost individual creativity and dauntlessness.

\section{Conclusion}

The current study aimed to uncover a layer of heroic stories. The expected result was to see how nature can influence a heroic quest. The nations behind these myths could be held to follow a certain cultural view point by having nature interfere in a hero's act in different parts of the quest. For instance, the Persian hero with a religious background relies on external forces such as nature to fulfill his heroic act; on the contrary, the Greek mythical character, who does not necessarily show allegiance to his divinity, goes on to have personal breakthroughs without having external aid from nature or other forces.

The out-come of these two different types of heroes seem to give out different results regarding the time following their achievement. People of Iran gain security, just rulers, and promised prophet, whereas the Greek hero gains an everlasting reputation of a dauntless adventurous soul with whom the nature shall sympathize and hold a proper memoriam for. Knowing how these two nations treated their heroes can bring out a lot of other hypotheses about them.

The reward giving system could be deduced from the type of help offered by nature. Iranian heroes who were striving for group values, lacked creativity and determination; therefore, nature was there to play an external reward and help. The Greek hero who followed his own personal whim did not expect external help and nature cherished this fearlessness after the hero's death. Yet in this paper, the final point made was although nature as an invisible omnipotent feature comes to be influential, it adhere to the reward system prevalent in the discussed societies.

\section{References}

Amozegar, J. (1998).The History of Iranian Mythology. Tehran: Samt Publications.

Amozegar, J \&Tafazoli, A. (2009).The $5^{\text {th }}$ Book of Dinkard. Tehran: Moein.

"Avesta". Encyclopcedia Britannica. Encyclopedia Britannica Online .Encyclopædia Britannica Inc., 2015.

$<$ http://www.britannica.com/EBchecked/topic/45645/Avesta> Web. 24 May. 2015.

Bahar, M. (1998).From Myth to History.Tehran: Cheshme Publications.

Bodkin, M. (1934).Archetypal Paterns in Poetry: Psychological Studies in Imagination. London.

Calame, C. (1999). The Rethoric of Muthos and Logos. Forms of figurative discourse, in R. Buxton (ed.) From myth

to reasonStudies in the development of Greek thought (Oxford): 119-43

Campbell, J. (1949).The Hero with a Thousand Faces. New York City: Pantheon Books.

Campbell, J. (2002).The Power of Myth. Trans. Abbas Mokhber. Tehran: Markaz Publications.

Deci, E. L., \& Ryan, R. M. (1985).Intrinsic Motivation and Self-determination in Human Behavior New York: Plenum Press.

Des Bouvrie, S. (2002). The Definition of Myth. Symbolical Phenomena in Ancient Culture. The Norwegian Institute at Athens.

De Zepetnek, S. (1999).From Comparative Literature Today toward Comparative Cultural Studies. CLCWeb: Comparative Literature and Culture1.3

Doostkhah, J. (2012). Avesta: the Eldest Persian Songs. Tehran: Morvarid Publications.

Hutcheon, L. \&Valdés, M. (1994).Rethinking Literary History Comparatively. New York: American Society of Learned Societies.

Nietzsche, F. (1990).Twilight of the Idols/The Anti-Christ, Penguin Books.

Ovid.(1893).Metamorphoses. Trans: Henry Riley. London: George Bell \& Sons.

Skinner, B. F. (1950). Are Theories of Learning Necessary? Psychological Review, 57, 193-216.

Tegano, D. W., Moran, D. J., III,\& Sawyers, J. K. (1991). Creativity in Early Childhood

Classrooms. Washington, DC: National Education Association.

Thompson, L. (1998). “Comparatively Speaking.” The New York Review of Books.

Todorov, T. (1997).Facing The Extreme: Moral Life in the Concentration Camps. Henry Holtand Company.

Vogler, C. (2007).The Writer's Journey: Mythic Structure for Writers. Michael Wiese Productions.

Voytilla, S. (1999).Excerpts from Myth and the Movies: Discovering Mythic Structure of 50 Unforgettable Films. Michael Wiese Productions.

Yarshater, E. (1972).Stories from Ancient Iran. Tehran: Ziba Publications. 